\title{
ARCHITECTURAL ANALYSIS: DISTINCTIVE BUILDING FEATURES IN PAKISTANI ARCHITECTURE
}

\author{
Quratulain Asghar* \\ Ume Fatima Abid** \\ Syed Muhammad Zille Ali Naqvi***
}

\begin{abstract}
This research attempts to analyze the recent trends in Pakistani architecture. It aims to explore three recent paradigms: regionalism and theme-based form generation. The purpose of the inquiry was to select and analyze projects from three different cities of Pakistan and draw comparisons and conclusions. The factors that can make any structure a trendsetter in relation to the architectural context of Pakistan have been analyzed. The study also attempts to analyze the latest trends in the architecture of the country. This methodology helped in comprehending the influential approaches of different architectural projects and assess these for persisting trends. The research also emphasizes on finding contemporary processes in expressing architectural design methodologies. The research analysis three case studies with the help of elaborated sketches and diagrams. The research is concluded by identifying building features that make each of them distinct in the context of sustainable and regionalism techniques. This study also highlights the unique design techniques that fall under the paradigms of Regionalism.
\end{abstract}

Keywords: Regionalism, form generation, trendsetting, contemporary architecture, Pakistan.

\section{INTRODUCTION}

The question which is being explored through this research is: what architectural components lead towards a building becoming a trendsetter? The current architecture in Pakistan can be expressed with the word "multiplicity", as it involves the response to traditional and non-traditional components, with the design being influenced by multiple historical backgrounds. Furthermore, the design is also impacted by the synchronicity and collocation of settings, like regulated and non-regulated developments. As a result, public and private projects explore new spaces and forms (Baldwin, 2019).

With the country having varied and diverse architectural history, evolving from Indo-Saracenic and Mughal style, there are many examples of Islamic architecture as well as modern projects. Architects today are also inclined towards mimicking international concepts and ideologies. The cities need an efficient building design that augments and repair the depleted urban milieu. One witness so many design examples that are anesthetized from inappropriate decisions that completely overlook the context, the climate, the user, and even the existing fabric and material directed to develop a new upmarket architecture.

The architecture of Pakistan has been re-inventing itself on the commercialization requirements. In this scenario, the kind of design that sets the precedent for the future in architecture is rare and difficult to find. Yet there are also some considerate examples produced from time to time. Some projects have run through the test of time and are timeless in true sense.

This research aims to draw attention towards a local innovative architecture based on regional needs and requirements, which can be identified as good examples.

\footnotetext{
* Quratulain Asghar, Assistant Professor, Department of Architecture, University of Engineering and Technology, Lahore, Pakistan. Email correspondance: quratulainasghar@gmail.com

** Ume Fatima Abid, Research Assistant, Department of Architecture, University of Engineering and Technology, Lahore, Pakistan. Email correspondance: fay008@gmail.com

$* * * \quad$ Syed Muhammad Zille Ali Naqvi, Principal Architect, Studioarch. Email correspondance: studioarch.za@gmail.com
} 
These projects have succeeded in producing a conscious and "out of the box" design. This study identifies three different, creative, and contemporary plans from three different cities of Pakistan. All three projects are completely varied in purpose, brief, scale, and even time of completion, but all three designs are innovative in their unique way.

\section{LITERATURE REVIEW}

This research emphasizes and delves upon the idea that if a building responds to the concept of Regionalism, it can play its part towards the regeneration and restoration of the environment through improved design and planning techniques and can connect better with the context.

Regionalism is an underlying idea that promotes the use of local architectural vocabulary and local building materials. Regionalism is an attitude that strives for close interaction with the perception of the 'genius loci', the 'spirit of the place'. The term 'Regionalism' is interpreted in some diverse ways in the architecture of the interwar period. It is an approach that can accommodate highly contradictory interests and viewpoints (Meganck, Santvoort and Maeyer, 2012). Any architect's approach to "Regionalism" should be very natural; he should try and design an amalgamation of a built environment that should root itself on the traditional as a well modern element in a balanced and unified way (Meganck, Santvoort and Maeyer, 2012). By using contextual forces, Regionalism imparts a sense of place and meaning to architecture. Regionalist designs are sensitive to the local climate as well as the technological constraints of the local building industry. The practitioners of Regionalism seek to integrate global architectural and technological developments with regional sensibilities derived from spatial, cultural, and historical contexts (Agrawal, n.d.).

On the other hand, one important theory on sustainability states that achieving sustainability should not be expensive. Stephen Mouzon in his recent book offers crucial remarks on the importance of doing less with more for a sustainable environment. He explains that sustainable design could be achieved without relying on costly technologies (Mouzon, 2010). The main lesson one may draw from Mouzon's research is how well one can do with less, by sharing resources and becoming less consumptive of finite resources and more efficient in everything one does.

The third component which needs to be adopted for design to be responsive is conceptual form generation. Concepts play a key role in the development of innovative design solutions for many architects and engineers. Even though there is no sharp distinction between the process of production and the process of interpretation of designs, an "intended" interpretation usually guides the actions of the designers. Conceptual descriptions set at the early stages of the design process are used to frame some general design approach. Design concepts are introduced contextually and in parallel to a course of productive design action that is described and explained in terms of them. Interpreting the output of the design action confers meaning on the concepts. This allows concepts and design artifacts to evolve in parallel (Kotsopoulos, 2008).

\section{RESEARCH METHODOLOGY}

The method of research for this paper relies on the data collected from the concerned architectural offices and telephonic interviews with the architects (whose design projects are incorporated in this paper). The research was carried out using photographic statistics gathered by the visit to the case studies and the information provided by the concerned architectural offices.

Through a technical examination of the planning and design details, the architectural elements have been identified, which contribute towards making the building responsive designs. The authors have looked at three buildings from three different cities of Pakistan for their innovative qualities based on the selection criteria which is (Figure 1):

i) Sustainability (only limited to the design concepts and techniques)

ii) Regionalism

iii) Conceptual form generation

\section{FINDINGS}

\section{Case study 01: Faran Mosque, Karachi: Responsive Design}

The project selected for this category is of Faran Mosque located in Karachi, designed by Architect Misbah Najmi and completed in 1984. It is located to the southeast of an intersection of two major Roads, Sharah-e-Faisal and Korangi

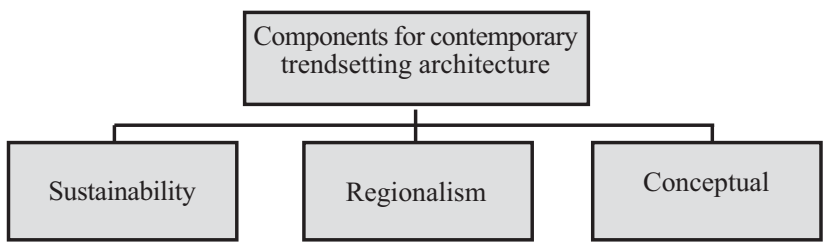

Figure-1: Compnents for trendsetting architecture. 
Road. Contextually it is placed next to an architecturally significant building Finance and Trade Center (FTC). The Mosque gratifies as a massive landmark, successfully avoiding competition with FTC in its background. The designof the Mosque evolved around the artificial hill, that provided a sound barrier and helped in achieving a conducive environment inside the mosque. The hill not only serves a meaningful purpose but helps promote a new ideology of design with the landscape becoming a part of the architectural vocabulary (Figures 2-5). The presence of courtyard and mechanical vents on the roof of the Mosque also assist in ventilation and air circulation. The Mosque has a central courtyard. Structurally, the Mosque comprises of RCC columns. Doors made up of wood and glass are embedded in them, opening into the central courtyard from three sides, except the qibla side. The ablution area is designed in such a manner that it doesn't affect the circulation of the Mosque, especially during the congregation.

This particular design incorporates the use of simple techniques by creating light wells, as vents in the basements, capturing natural ventilation through a sunken courtyard
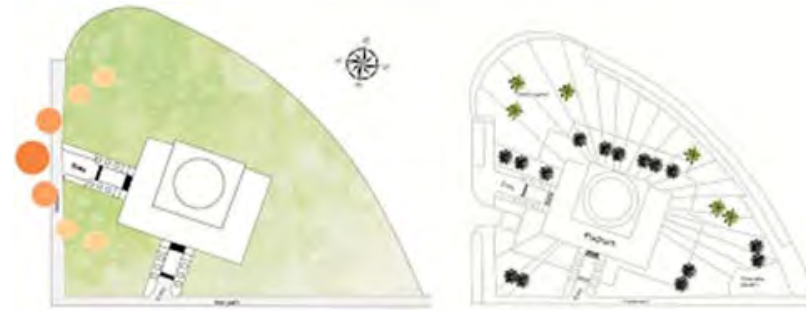

Figure-2: Master plan of the site and the Mosque.

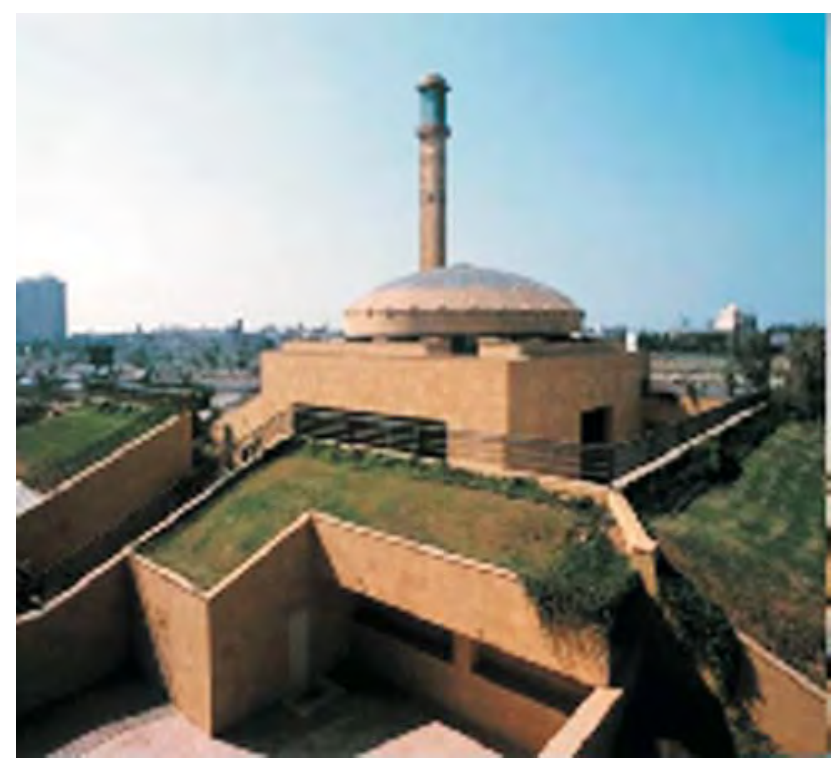

Figure-3: Monumentality in architecture. Source: Info 360, 2017

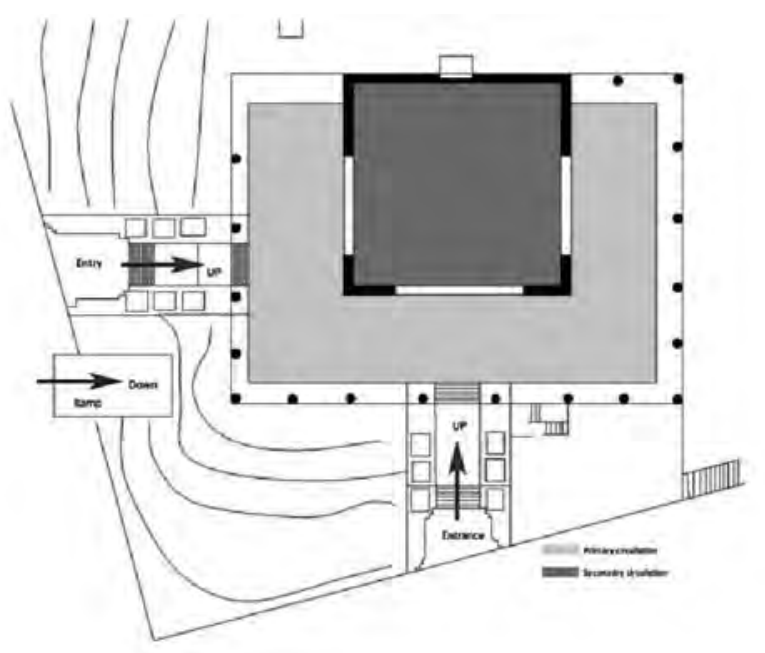

Figure-4: Ground floor plans. Source: Info 360, 2017

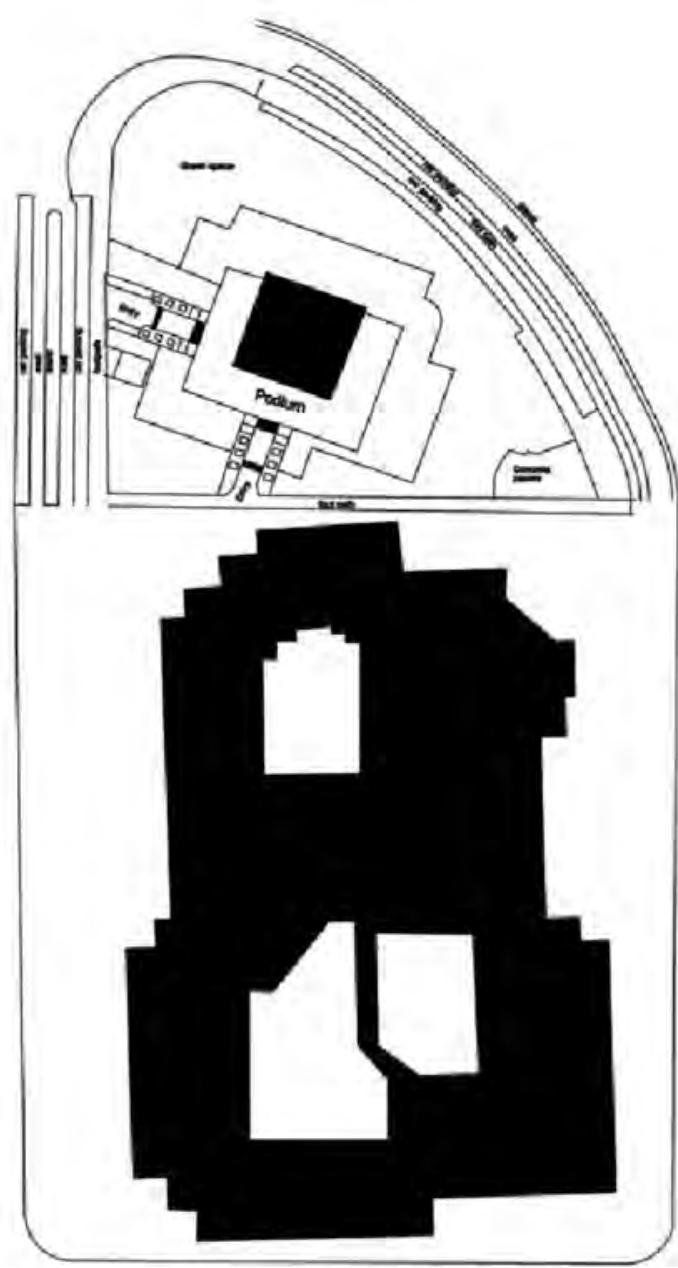

Figure-5: Figure ground diagram. 
and incorporation of cooling technique and usage of slopes as noise barrier (Figures 6-7). These slopes allow the building to harness energy. Variation in levels is created to control noise pollution and ventilation. Another technique known as cooling through evaporation is used throughout the design. Water sprinklers are provided on the west and southern sides and are scheduled to be used in the afternoon. The wind hits the wet slopes, gets cool, and keeps the temperature down, the local stone absorbs the water and thus proves to be a sustainable solution. Sunlight is carefully brought into the building to pawn humidity through the drying effect. Traditional architectural techniques popularly known as "wind catchers" are also used, to supply fresh air to the basement and replace the warm air. These wind catchers help in cross ventilation, as the overall climate of Karachi is windy.

The sprinklers placed in the windward direction help in getting the overall temperature of the mosque down, especially in the open court. The sunken courtyards also create a micro-climate within the prayer space. A fiberglass dome for capturing maximum natural light is used, and the incorporation of jalis (screens) serves as an aesthetically pleasing element as well as produces a cooler environment. These traditional methods are cost-effective and natural.

There is also the use of active techniques that are facilitated mechanically. The relationship of the building geometry with ecology is often described by commonplaces such as compact shapes that are most favorable for the use of energy and building materials. The geometric analysis of this Mosque reveals the sensitive approach of merging shapes that complement each other (Figure 8).

The overall design analysis reveals that the designer has indulged in the attribute of sustainability in multiple ways. From air circulation to material selection, this Mosque is fully aligned with nature and sets a trend for future architects to produce such projects that work on less input and maximum output (Figure 9).

\section{Case study 02: Telenor office (345), Islamabad}

The Telenor office (345) in Islamabad is designed by the Architectural firm, Arcop (PVT) Ltd, and the project got completed in 2017. The building has a strong conceptual base and is inspired by traditional contextual features of the region, incorporating the element of Baaoli (originating fin the sub-continent, these are sub-level wells or ponds, which are reached by steps) (Figure 10). In incorporating this concept, the building has developed a Regional connection both in physicality and in theory. that the natural topography of the site remains unchanged and the building planning and contours accept and embrace the natural contours of the site. The development of courtyards reflects the traditional and regional influence on the design at a larger scale, and are linked up with the detailed analysis of the shapes and modules that are morphed to create the

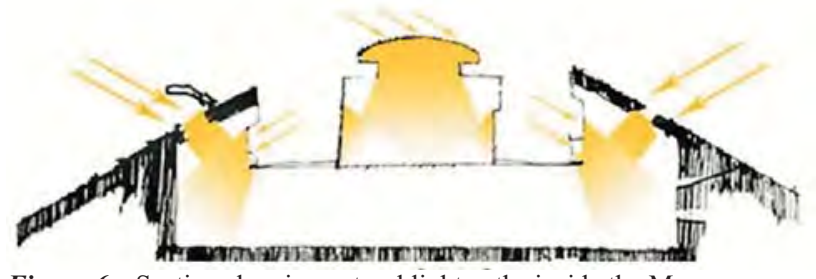

Figure-6: Section showing natural light paths inside the Mosque.

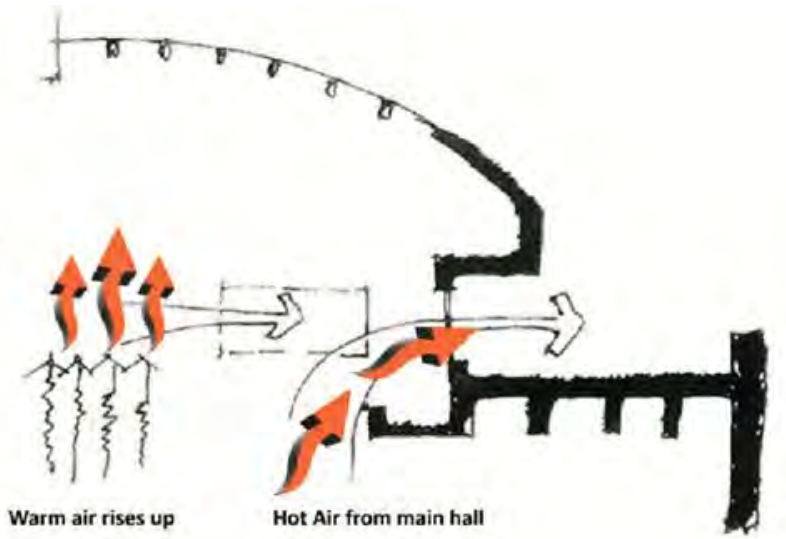

Figure-7: Section explanining the passive and wind catching techniques in design.

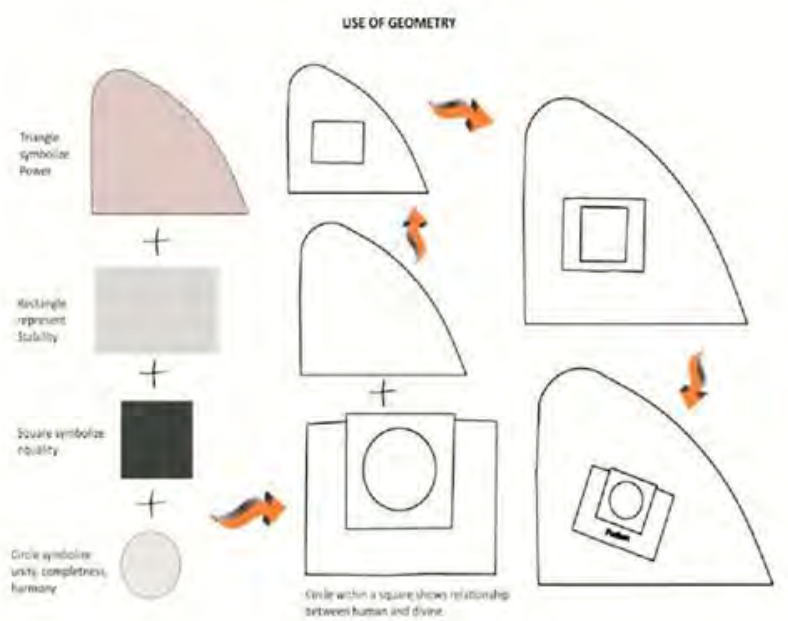

Figure-8: Useof geometry in design. Source: Info $360,2017$.

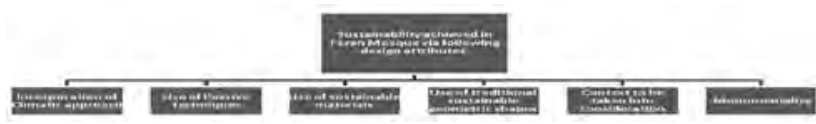

Figure-9: Analytical points of incorporation of sustainability into Faran Mosque Design. 

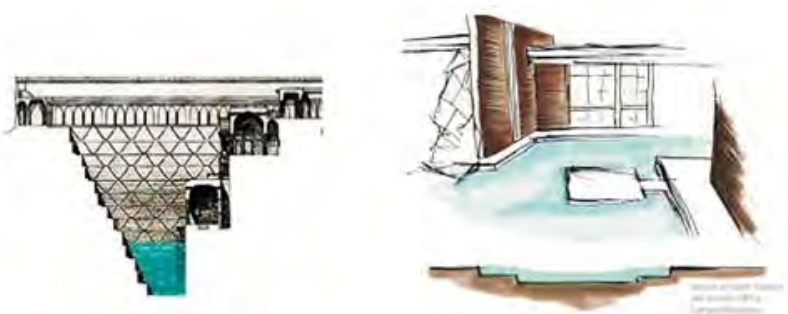

Figure-10: Use of central courtyard for collection of water concept of Chand Baori in India.

Source: Arch Daily, 2019.
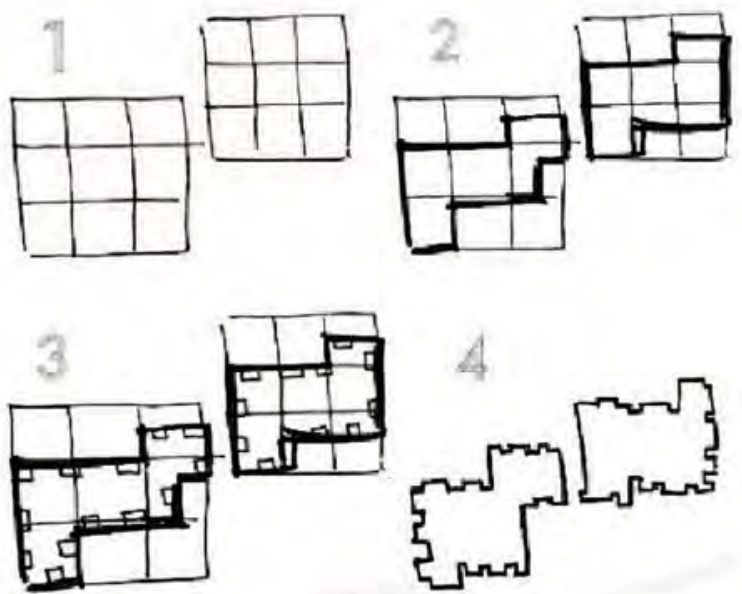

Figure-11: Use of schematic repetition for future extension in a site plan.

courtyards (Figures 11-12). The use of geometrical intricate details within the jaalis on a smaller scale, as compared to the whole building, reflects the geometrical exploration and modular design in the plans. The use of modules within the plan resembles the historic plans of Punjab's villages with a large number of small houses surrounding central courtyards.

with the surrounding landscape makes the building aesthetically pleasing (Figure 13). Minimum openings are provided on the east-west side of the building, which has been protected by rammed earth flanked walls. Regionalism as a concept is incorporated in this building's design. Incorporation of traditional and cultural design elements,

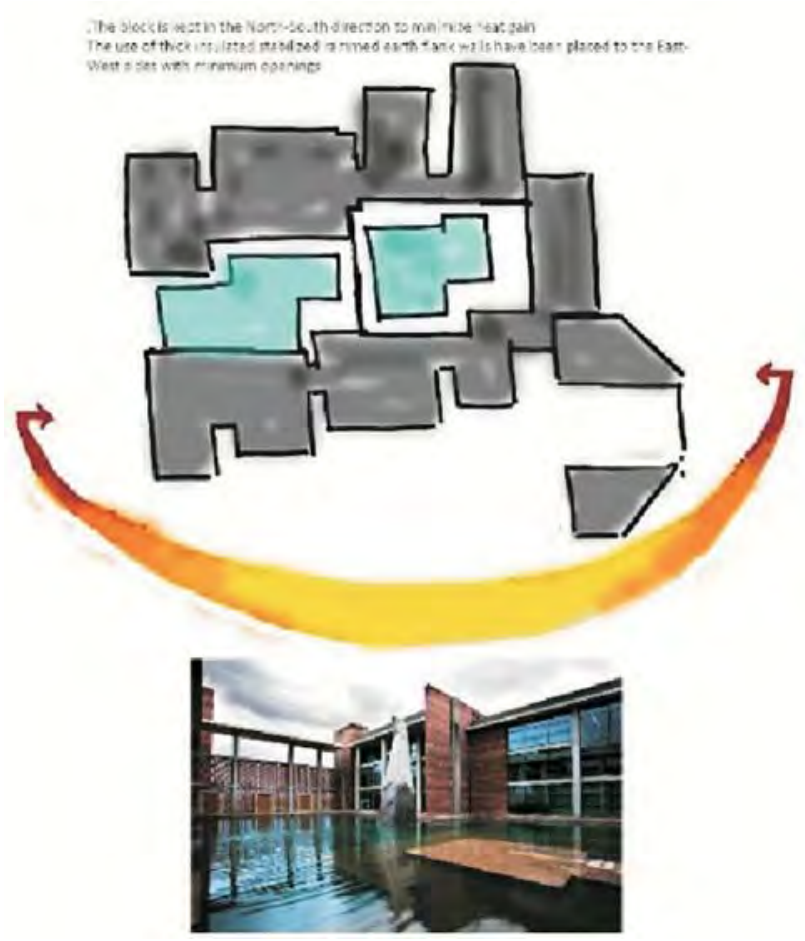

Figure-12: Strategic placement of courtyards.

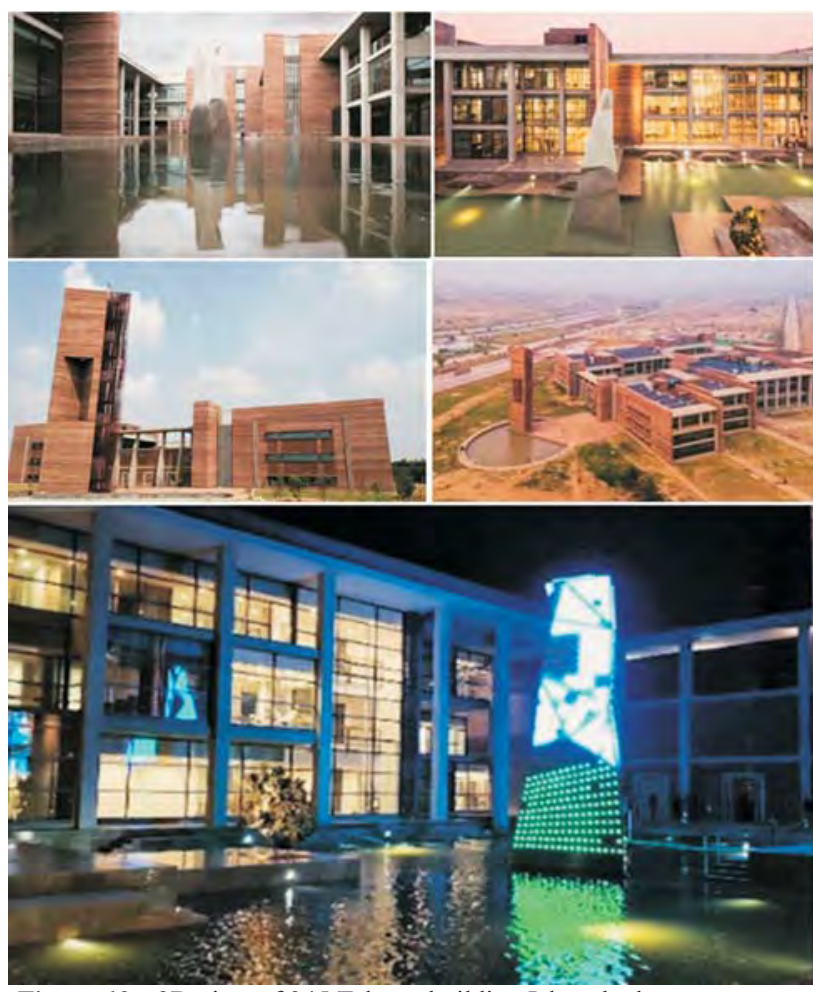

Figure-13: 3D view of 345 Telenor building Islamabad.

Source: Arch Daily, 2019 


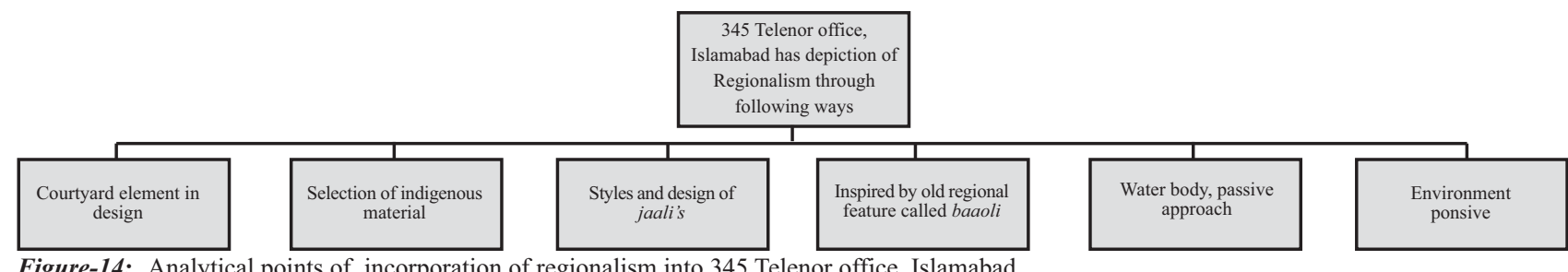

Figure-14: Analytical points of incorporation of regionalism into 345 Telenor office, Islamabad.

like the use of flanked earth walls, courtyards, blending subtly with the use of wood in exteriors shows regional connections. The design focusses on developing spaces that are not rigid, and follow a hierarchy and allows users to communicate freely. The central courtyards originate from the concept of central gathering spaces that were common in the traditional regional architecture. Large window openings are provided on either side of the building which connects to the central courtyard, for better light and ventilation. The water body in the center of the master plan naturally cools down the air within the courtyards and allows cool air to enter the building. Figure 14 summarizes the implementation of the component of regionalism into this design.

\section{Case study 03: Garrison Shooting Gallery, Lahore: Form Generation}

The Lahore Garrison Shooting Gallery is designed by Raees Faheem Associates, a Lahore based architectural design firm. The project was completed in 2018. The design of this project serves as an opportunity to study the extensive modern design principles incorporated in this structure cum monument (Figure 15). The building is inspired by the design of a bunker and the architecture of a fort. It is enveloped by artificial contours and stands as a symbol of modern architecture. It is an interesting amalgamation of dominating circular vocabulary punctuated with functional zones. The defined spaces capture the ideal views of the surroundings.

The distinctive building feature is its circular language. The concept of a concealed bunker fits the functional requirement of the building too since it's an army owned shooting gallery. Bunkers are spaces where shooting is the focal activity. The Building is depressed within the depths of contours. On each side of the built form, natural and artificial contours embed the building. This was achieved by dumping large amounts of earth excavated and dumped on the site and shaped into layers with mechanical means.

The ratio of open areas is considerably more as compared to the built structure, because of the nature of the activity, which requires larger distances of unobstructed views. As

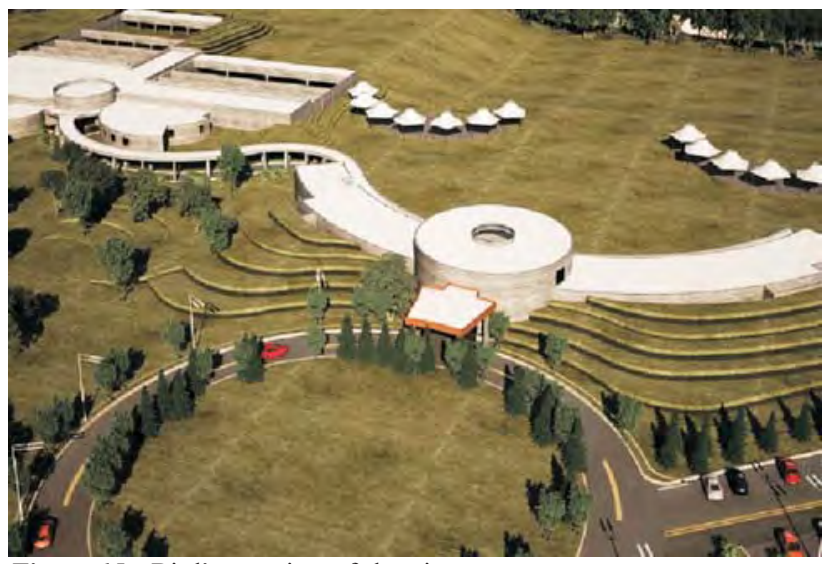

Figure-15: Bird's eye view of shooting range. Source: Raees Faheem Associates, 2019.

the project is located in a scarcely populated area, hence the less negative impact of the sound from the range on its surroundings.

The interior of the building receives sufficient natural light, which is important for the semi-covered ranges because they don't need artificial lighting during the day. The open spaces have perforated roofs where lights need to penetrate and the areas which have heavy visitor circulation are shaded. The height of the structure does not go above two floors, hence it does not obstruct any wind or create unlikely shadows. The plan is introverted in nature (Figure 16). The proportions of the building are well worked out, creating an overall balance in the composition. The repetition of the circular pattern throughout the design is very calculative, for instance, the circular arch can easily be added where needed. This additive property is inherent in the entire composition, where the whole can be divided into different parts wherever required (Figure 17).

A relationship is developed with adjacent circles with converging tangential lines, and those lines and circles further connect with circles of varying sizes. Eventually, a plan has been extruded from the circumference of the circles. If the circles and lines had been of equal size and direction, its design would turn out to be a monotonous repetition with neither multiplicity nor unity within the geometry. Artificially 

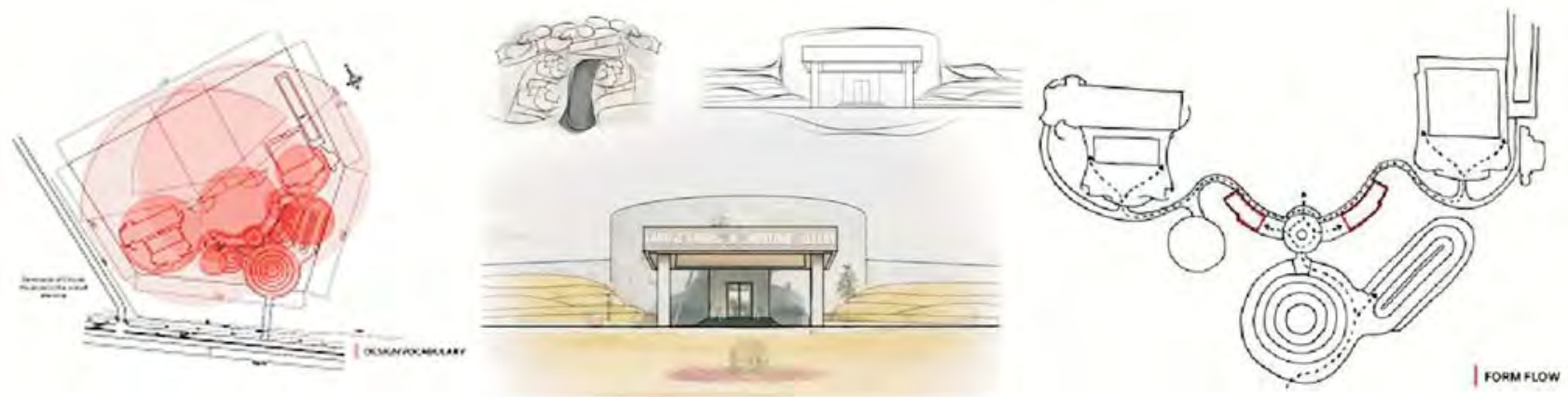

Figure-16: Design Vocabulary.

added contours are the major design elements of this building, as they enhance both the concept and function of the shooting gallery. The contours visually obstruct the view from the front of the building to the back, which helps to create privacy, supporting the nature of the activity. The contours also add visual contrast and interest from the surroundings. These contours also recreate natural hunting and shooting grounds, giving similar vibes (Figure 18).

Overall, this design has responded to the component of form generation as documented in Figure 19.

\section{DISCUSSION:}

The design of any building should evolve out of contextual, regional, and conceptual constraints. It is pertinent to pay consideration to the practicality of design but at the same time, the study of its impact on the regional and contextual platform is also very pertinent. This research throws light on the regional and conceptual local design features that are helpful for architects to understand the necessity and use of these components. The analysis has addressed design elements that give the building's individuality. Table 1 summarizes the key findings and links them with the three case studies.

\section{LIMITATIONS}

The major limitation of this research was that there was very little literature available on the subject of architecture in Pakistan, due to which there is a shortage of pertinent
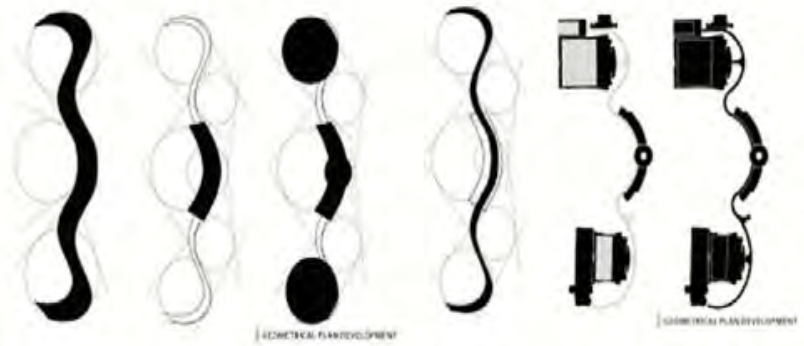

Figure-17: Geometrical Plan Development Analysis.
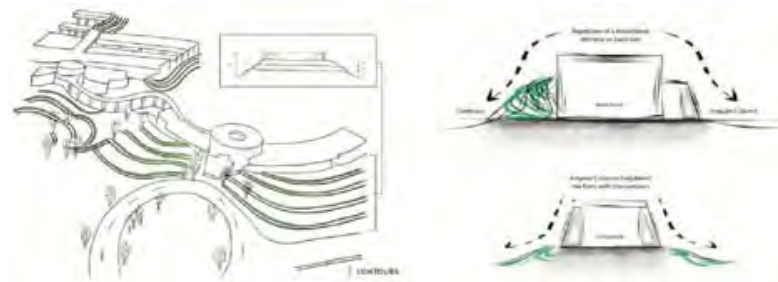

Figure-18: Contours analysis and form influence.

references and authors have relied majorly on technical examination of the buildings. Hence, the idea is to enhance the limited material available on the existing architectural literature in Pakistan. This paper aims to analyze these existing architectural structures which have helped in bringing innovation through their design techniques. These criteria are completely independent of each other. The intention was to dig out important components that should become an integral part of the design of a building and how the incorporating of these strategies can lead to an innovative structure.

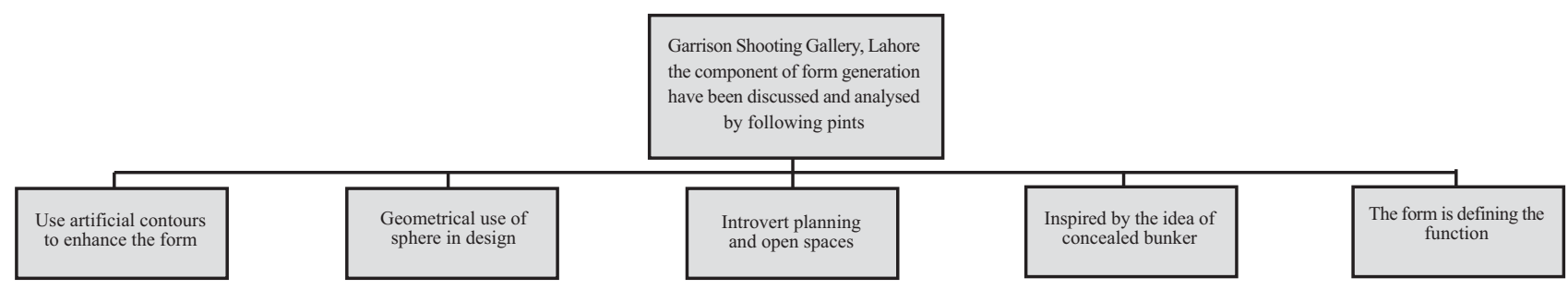

Figure-19: Analytical points of incorporation of form development into garrison shooting range. 
Table-1: Summary of the Key Findings of the Three Case Studies.

\begin{tabular}{|c|c|c|}
\hline \multirow{4}{*}{$\begin{array}{l}\text { CLIMATICALLY } \\
\text { RESPONSIVE } \\
\text { DESIGN }\end{array}$} & STATEMENT 1 & Faran Mosque, Karachi \\
\hline & $\begin{array}{l}\text { Sustainability is a comprehensive concept, as defined } \\
\text { by United Nations' Brunt land Commission in } 1987 \\
\text { "meeting the needs of the present without } \\
\text { compromising the ability of future generations to } \\
\text { meet their own needs" (Al-Kodmany, 2018) }\end{array}$ & \multirow{3}{*}{$\begin{array}{l}\text { Cultural understanding, contextual } \\
\text { study, and enhanced design features } \\
\text { have been seen in this project to sustain } \\
\text { for a longer time. } \\
\text { Design is aligned with nature having a } \\
\text { passive effect on the environment. } \\
\text { The natural environment has been taken } \\
\text { into consideration while designing the } \\
\text { building. From air circulation to the } \\
\text { selection of material, everything has } \\
\text { been chosen which is environmentally } \\
\text { friendly. }\end{array}$} \\
\hline & STATEMENT 2 & \\
\hline & $\begin{array}{l}\text { Climatically responsive design architecture focuses } \\
\text { upon the relationship between the human and their } \\
\text { environment. The humans must not build something } \\
\text { which harms the environment (Archana, 2013) }\end{array}$ & \\
\hline \multirow{4}{*}{ REGIONALISM } & STATEMENT 1 & 345, Telenor Office, Islamabad \\
\hline & $\begin{array}{l}\text { Any architect's approach to "regionalism" should be } \\
\text { very natural; he should try and design an amalgamation } \\
\text { of a built environment that should root itself on the } \\
\text { traditional as a well modern element in a balanced } \\
\text { and unified way (Meganck, Santvoort, \& Maeyer, } \\
\text { 2012). }\end{array}$ & \multirow{3}{*}{$\begin{array}{l}\text { Regionalism defines many aspects and } \\
\text { general methods of expressing the } \\
\text { natural environment including climate } \\
\text { and context. } \\
\text { Geometrically the use of modules } \\
\text { within the plan resembles the historic } \\
\text { planes of Punjab's villages with the } \\
\text { large number of small houses } \\
\text { surrounding central courtyards. } \\
\text { Traditional and cultural methods and } \\
\text { elements of design are incorporated in } \\
\text { a modern way with modern techniques. }\end{array}$} \\
\hline & STATEMENT 2 & \\
\hline & $\begin{array}{l}\text { It is an architectural practice that endeavors to counter } \\
\text { the homogeneity inherent in modernist architecture } \\
\text { (Kaur and Prabhjot, 2016) }\end{array}$ & \\
\hline \multirow[b]{2}{*}{$\begin{array}{l}\text { CONCEPTUAL } \\
\text { FORM } \\
\text { GENERATION }\end{array}$} & STATEMENT 1 & Garrison Shooting Gallery, Lahore \\
\hline & $\begin{array}{l}\text { Geometrical elements are used as an important factor } \\
\text { that implies the appeal of an arrangement of } \\
\text { architectural form and space (Meganck, Santvoort, } \\
\text { and Maeyer, 2012). The generation of form and space } \\
\text { by utilizing basic geometrical elements makes them } \\
\text { imperative inputs in architectural design. Generating } \\
\text { the architectural form and space based on the } \\
\text { geometrical rules and abstracting them within basic } \\
\text { geometrical elements make the result more } \\
\text { understandable and recognizable (Yilmaz, 1999) }\end{array}$ & $\begin{array}{l}\text { In the architectural profile of the project, } \\
\text { an interesting amalgamation of } \\
\text { dominating circular vocabulary } \\
\text { punctuated with functional zones and } \\
\text { defined spaces combined with ideal } \\
\text { views, this building captivates all. The } \\
\text { greenery flows seamlessly into the } \\
\text { building as a perfect example of } \\
\text { introverted planning. } \\
\text { The plan has been extruded from the } \\
\text { circumference of the circles. } \\
\text { There is a strong link between } \\
\text { geometry, nature and design in this } \\
\text { project. }\end{array}$ \\
\hline
\end{tabular}

\section{CONCLUSIONS}

The local examples analyzed here have embraced sustainable design features and contextual relationships in unique ways and at the same time, these are boldly and subtly ironic. The buildings discussed here can be termed as hybrid designs, which embrace an eclectic approach incorporating consciously selected features without adhering to one inspired theme. This option is striking and communal, so long as architects use the freedom to plan their design by steering and mixing various design solutions. This technique may allow clients and architects to work together to augment their design choices. Therefore, architects need not adapt, morph, or twist their design spaces several times to fit a particular design theme. They can employ a wide-spectrum of arrangements that simultaneously integrate a plethora of 
Table-2: Summary of Design Approaches Concerning the Case Studies.

\begin{tabular}{|c|c|c|c|c|c|}
\hline \multicolumn{3}{|r|}{ Design Approach } & \multicolumn{3}{|c|}{ CASE STUDY } \\
\hline & TECHNIQUES & USAGE & 1 & 2 & 3 \\
\hline 1 & $\begin{array}{l}\text { Traditional } \\
\text { techniques }\end{array}$ & $\begin{array}{l}\text { The project's architectural style collaborates with } \\
\text { traditional techniques. }\end{array}$ & & & \\
\hline 2 & $\begin{array}{l}\text { Passive } \\
\text { techniques }\end{array}$ & $\begin{array}{l}\text { Design techniques, like windcatchers have been used } \\
\text { to replace dry/warm air effects with the cool air. } \\
\text { The architect made this building a climatic responsive } \\
\text { building by incorporating certain elements which } \\
\text { include the sunken courtyard, light wells, wind catchers } \\
\text { align along the wind direction and aided with } \\
\text { mechanical vents. The incorporation of the water body } \\
\text { naturally cools down the air within the courtyards and } \\
\text { with the help of cross ventilation, allows cool air to } \\
\text { enter into the building. }\end{array}$ & & & \\
\hline 3 & $\begin{array}{l}\text { Contextual } \\
\text { response }\end{array}$ & $\begin{array}{l}\text { The architect also incorporated landscape design. He } \\
\text { created artificial hills all four sides that promote } \\
\text { aesthetics and attain connection with the built form. }\end{array}$ & & & \\
\hline 6 & Geometry & $\begin{array}{l}\text { Geometric concepts were used in different ways in } \\
\text { the design including planning, façade, sections, form, } \\
\text { space, and in details like columns. The design } \\
\text { developed strong links between geometry, nature, and } \\
\text { space. }\end{array}$ & & & \\
\hline 8 & Materials & $\begin{array}{l}\text { The materials that have been used are environmentally } \\
\text { responsive and are locally available. }\end{array}$ & & & \\
\hline
\end{tabular}

design features. This paper emphasizes and suggests seeking a hybrid/eclectic design approach. A summary of these design approaches is provided in Table 2.

Responsive techniques should be used in architecture, to reduce energy consumption and pollution linked with construction. Architects should be trained to follow simple techniques of developing conceptual design not only at a cognizant level but also at subliminal level; they should be naturally apt and trained towards using transformation techniques of vernacular and traditional architecture and use different strategies to design, while strongly keeping the context, users and local materials in mind. The design approach should try to amalgamate the traditional methodology with contemporary styles, to re-establish the lost and evolve a new identity for architecture in a given context. All the three projects dissussed here have adopted this amalgamation technique. In Telenor building, the Architect beautifully created moving grid-like patterns through a series of linking courtyards, and the building materials (bricks) were used on a modular grid in the plan as well as in the façade, reflecting rational and modern approach. The Faran Mosque took inspiration from modern Islamic architecture and successfully created spaces responding to the local climate and completely avoiding unnecessary ornamentation. For the architects, Regionalism as a concept did not become a technique only to resolve the energy crisis, but was used to achieve a greater objective of designing responsive buildings.

\section{RECOMMENDATIONS}

A building's design and aesthetics should be consciously taken through an iterative process, and with the help of available powerful modeling tools, design teams may decide on how specific elements, such as aerodynamic forms, structural systems, vertical landscaping, renewable energy features, and shading devices can be applied to improve the overall design.

Today the need is to find new architectural meaning, methodologies that are flexible, aligned with nature, and also breaking past typologies and setting new trends. A design strategy should be based on the perception of form that creates equilibrium between the site, the context, the building and its user. The use of new tools and techniques should become an integral part of the design process to produce responsive architecture. 


\section{REFERENCES}

Agrawal, V., (n.d.), Regionalism in Architecture as an Expression of Appropriate Technology and Sustainably. Haryana, India.

Al-Kodmany, K., 2018, Sustainability and the 21st Century Vertical City: A Review of Design Approaches of Tall Buildings, Buildings, viewed 22-10-2019, Retrieved from www.mdpi.com/journal/buildings

Arch Daily, 2019, Arch Daily Projects, viewed 22-10-2019, from 345 Telenor Campus / Arcop (Pvt) Ltd.: https://www.archdaily.com/897638/345-telenor-campus-arcop-pvt-ltd

Archana, K., 2013, “A Conceptual Study of Sustainable Development in the Era of Globalization”, International Journal of Scientific and Research Publications, Vol 3 (5):1-3.

Baldwin, E., 2019, Building Up: Modern Architecture in Pakistan viewed 2-6-2019, from archdaily: https://www.archdaily.com/929649/building-up-modern-architecture-in-pakistan

Info 360, 2017, Info 360 Architecture Database. viewed 5-5-2019, from http://www.info-360.com/modern-masjid-designby-najmi-bilgrami-collaborative-farhan-mosque-karachi/

Kaur, G., and Prabhjot, S., 2016, Charles Correa: Seeking new Identity of Indian Architecture through "Critical Regionalism", Journal of Civil Engineering and Environmental Technology, Vol, 4(2): 116-122.

Kotsopoulos, S. D., 2008, Design Concepts in Architecture: The Porosity Paradigm, International Journal of Architectural Computing, 3(6): 335-360.

Meganck, L., Santvoort, L. V., and Maeyer, J. D., 2012, Regionalism and Modernity: Architecture in Western Europe 19141940, Minderbroedersstraat 4, Leuven University Press.

Mouzon, S. A., 2010, The Original Green: Unlocking the Mystery of True Sustainability (1st ed.). New York, New Urban Guild Foundation.

Raees Faheem Associates, 2019, Raees Faheem, viewed 22-6-2019, from http://raeesfaheem.com Yilmaz, S, 1999, Evolution of the Architectural Form Based on the Geometrical Concepts, Izmir, Turkey, Izmir Institute of Technology. 